\title{
Photoelectrochemical Studies on High Specific Capacitance-Photoactive Interfaces Based on Poly 3,4- Ethylenedioxythiophene/Metal Oxides Assemblies
}

\author{
Kasem K. Kasem*, William Bennett, Heather Ramey, Nick Daanen \\ School of Science, Indiana University Kokomo, Kokomo, IN, USA \\ Email: "kkasem@iuk.edu
}

Received 6 March 2015; accepted 18 May 2015; published 22 May 2015

Copyright (C) 2015 by authors and Scientific Research Publishing Inc.

This work is licensed under the Creative Commons Attribution International License (CC BY). http://creativecommons.org/licenses/by/4.0/

(c) (i) Open Access

\begin{abstract}
Inorganic/organic interfaces (IOI) consist of $\mathrm{TiO}_{2}$ /PEDOT (poly 3,4-ethylenedioxythiophene) and $\left[\mathrm{PMo}_{12} \mathrm{O}_{40}\right]^{3-}$ or $\mathrm{MoO}_{3} / \mathrm{PEDOT}$ were subject to photoelectrochemical studies in both aqueous nanosuspensions and in thin solid films. The effects PEDOT modifier caused on the photoelectrochemical behavior of the IOI were investigated using $\left[\mathrm{Fe}(\mathrm{CN})_{6}\right]^{4-}$ as the photoactive hydrated electron donor agent. Results show that native PEDOT or PEDOT doped with $\mathrm{MoO}_{3}$ thin films increased charge storage capability evident by the high capacitive current. In the case of nano suspensions composed of $\mathrm{TiO}_{2} / \mathrm{PEDOT}$ the adsorption process of $\left[\mathrm{Fe}(\mathrm{CN})_{6}\right]^{3-}$ (photolysis product) control of the photoactivity outcome of the IOI assemblies. $\mathrm{TiO}_{2}$ /PEDOT shows a lower heterogeneous photochemical response than native $\mathrm{TiO}_{2}$ in short term photolysis times. At longer photolysis times the IOI shows photoactivity greater than that of native $\mathrm{TiO}_{2}$. The interface activities were explained by analyzing the IOI junction characteristics, such as electron affinity, work function and hole/electrons barrier heights. The aqueous nano-systems retained moderate stability as indicated by the reproducibility of their photocatalytic activities. Both $\left[\mathrm{Fe}(\mathrm{CN})_{6}\right]^{4-}$ and PEDT contributed to the stability of native $\mathrm{TiO}_{2}$ surfaces.
\end{abstract}

\section{Keywords}

Inorganic/Organic Semiconductors, Photoelectrochemical Cells, High Capacitive Assembly

${ }^{*}$ Corresponding author.

How to cite this paper: Kasem, K.K., Bennett, W., Ramey, H. and Daanen, N. (2015) Photoelectrochemical Studies on High Specific Capacitance-Photoactive Interfaces Based on Poly 3,4-Ethylenedioxythiophene/Metal Oxides Assemblies. Journal of Materials Science and Chemical Engineering, 3, 88-97. http://dx.doi.org/10.4236/msce.2015.35010 


\section{Introduction}

Polymers of conjugated organic compounds possess large molar absorptivity which is a desired quality in the absorption of light. This was an attractive characteristic for the use of these polymers in photovoltaic cells for solar energy harvesting, conversion and storage devices. Some of these polymers can be prepared electrochemically under very controllable conditions. The use of electrochemical polymerization methods made it is possible to modify surfaces and create photoactive interfaces. Surface modification can be a very effective way to create or eliminate defects and alter the energy band at inorganic/organic Interfaces. This will also alter the donor/acceptor character of the IOI assemblies. Poly (3,4-ethylenedioxythiophene) (PEDOT) and its derivatives are well known as very stable conducting polymers [1]-[6]. As p-conjugated conducting polymers are excellent materials for creation of photoactive interfaces due to their ability to act as electron reservoirs, thereby giving rise to colored, mixed-valence state species while retaining their structural integrity. PEDOT has been prepared by several methods including emulsion techniques [1], protein-mediated synthesis [2], vapor phase polymerization [3], solid state synthesis [4], and by electrochemical synthesis [5] [6].

PEDOT was subject to several investigations related to its applications in as flexible electrodes for energy storage and conversion [7], hybrid super capacitor materials [8], for use in dye-sensitized solar cells [9], as chemiresistive sensors for detection of nitro-aromatics [10], for dip-pen nanolithography [11], and PEDOT-based nano-coatings for tissue regeneration has been investigated [12]. These materials have also been used for construction of inorganic/organic interfaces, where the reversible electro-switchable luminescence in thin films of organic-inorganic hybrid assemblies was reported [13].

The great stability of PEDOT and its ability to act as electron donor (p-Type) substantiate the interest to investigate its usefulness in conjunction with the well-known stable photoactive semiconductor $\mathrm{TiO}_{2}$, and in conjunction with the multi-redox active centers $\mathrm{MoO}_{3}$. The performance of $\mathrm{TiO}_{2} / \mathrm{PEDOT}$, and $\mathrm{MoO}_{3} / \mathrm{PEDOT}$ assembly interfaces will be examined monitoring their effectiveness in charge separation, exchange, storage, and transfer.

\section{Experimental}

\subsection{Reagents}

All the reagents were of analytical grade. All of the solutions were prepared using deionized water, unless otherwise stated. $\mathrm{TiO}_{2}, \mathrm{TiO}_{2} / \mathrm{PEDOT}$ were either in nanoparticulate form or thin solid films.

\subsection{Preparations}

1-PEDOT: This polymer was prepared by both electrochemical and photochemical techniques:

\subsubsection{Electropolymerization of EDOT}

Polymer thin films were generated electrochemically using cyclic voltammetry (CV) by repetitive cycling of the FTO electrode potential at a scan rate $0.10 \mathrm{~V} / \mathrm{s}$ between -1.5 and $1.2 \mathrm{~V}$ vs $\mathrm{Ag} / \mathrm{AgCl}$ in acetonitrile solution of $0.2 \mathrm{M} \mathrm{LiClO}_{4}$ containing $10 \mathrm{mM}$ of the monomer.

\subsubsection{Preparation of $\mathrm{TiO}_{2} / \mathrm{PEDOT} /$ Interface}

Colloidal suspensions of $\mathrm{TiO}_{2} / \mathrm{PEDOT}$ interface were prepared as follows: $0.05 \mathrm{~g}$ of $\mathrm{TiO}_{2}$ nanoparticles prepared as reported previously [14] were suspended in the solution of EDOT in acetonitrile. The mixture was subjected to a 10 minute sonication followed by stirring for 1.0 hour to allow maximum adsorption of EDOT on the $\mathrm{TiO}_{2}$ nanoparticles. The excess EDOT was removed by centrifugation. $\mathrm{TiO}_{2}$ with adsorbed EDOT was re-suspended in deionized-water containing a few drops of $30 \% \mathrm{H}_{2} \mathrm{O}_{2}$ and subjected to UV radiation under constant stirring for 3 hours. The resultant $\mathrm{TiO}_{2} / \mathrm{PEDOT}$ was rinsed several times with deionized water and allowed to dry at $120^{\circ} \mathrm{C}$ for 2 hours.

\subsubsection{Electropolymerization of $\mathrm{EDOT} / \mathrm{MoO}_{3}$}

Thin films of PEDOT containing clusters of $\mathrm{MoO}_{3}$ were generated electrochemically using cyclic voltammetry (CV) by repetitive cycling of the FTO electrode potential at a scan rate $0.10 \mathrm{~V} / \mathrm{s}$ between -0.4 and $1.2 \mathrm{~V}$ vs $\mathrm{Ag} / \mathrm{AgCl}$ in mixed solvent of dioxane/water containing $1 \mathrm{mM}$ of the monomer EDOT, $0.5 \mathrm{mM}$ of phosphomo- 
lybdic acid $\left(\mathrm{H}_{3} \mathrm{PMo}_{12} \mathrm{O}_{40}\right)$ and $0.5 \mathrm{M} \mathrm{H}_{2} \mathrm{SO}_{4}$.

\subsubsection{Deposition of $\mathrm{TiO}_{2} / \mathrm{PEDOT}$ Thin Solid Films}

Thin solid films of $\mathrm{TiO}_{2}$ particles, modified with PEDOT (prepared as described in B) were suspended in acetonitrile solution of polyvinyl pyridine (PVP). The suspension was spread evenly over fluorine doped Tin oxide (FTO) slides $(12.5 \times 75 \mathrm{~mm})$ and dried at $120^{\circ} \mathrm{C}$ for 6 hours. The assembled electrode was transferred to a three-electrode cell containing the chosen buffer as the electrolyte and a Ag/AgCl and Pt electrodes as the reference and counter electrode respectively.

\subsection{Instrumentation}

All electrochemical experiments were carried out using a BAS $100 \mathrm{~W}$ electrochemical analyzer (Bioanalytical Co). Steady state reflectance spectra were obtained using Shimadzu UV-2101 PC. Irradiation was performed with a solar simulator 300 watt xenon lamp (Newport) with an IR filter. Photoelectrochemical studies on thin solid film were performed on an experimental setting as illustrated in (Diagram 1(a)). The electro/photolysis cell was a one-compartment Pyrex cell with a quartz window (Diagram 1(b)) facing the irradiation source [15]. The working electrode, a $10.0 \mathrm{~cm}^{2}$ platinum gauze cylinder, had a solution volume of $100 \mathrm{~mL}$. Suspensions were stirred with a magnetic stirrer during the measurements. $\mathrm{A} \mathrm{Ag} / \mathrm{AgCl} / \mathrm{Cl}$ reference electrode was also fitted into this compartment. A $10-\mathrm{cm}^{2}$ platinum counter electrode was housed in a glass cylinder sealed in one end with a fine-porosity glass frit.

Photolysis of $\left[\mathrm{Fe}(\mathrm{CN})_{6}\right]^{4-}$ generated hydrated electrons and $\left[\mathrm{Fe}(\mathrm{CN})_{6}\right]^{3-}$. The potential of the working electrode was fixed at $100 \mathrm{mV}$ more negative than the reduction potential of $\left[\mathrm{Fe}(\mathrm{CN})_{6}\right]^{3-}$ to guarantee full reduction of ferricyanide. The current due to the reduction of $\left[\mathrm{Fe}(\mathrm{CN})_{6}\right]^{3-}$ collected by the working electrode during the photolysis process is a measure of photocurrent. The measured photocurrent was normalized considering two photons per one hydrogen molecule, and was used to calculate the number of moles of hydrogen generated per square meter per hour of illumination.

Unless otherwise stated, all experiments were performed at room temperature $25^{\circ} \mathrm{C} \pm 1{ }^{\circ} \mathrm{C}$.

\section{Results and Discussions}

\subsection{Electropolymerization of EDOT}

Controlled deposition of polymer film took place by repetitive cycling of the FTO electrode potential at scan rate of $0.10 \mathrm{~V} / \mathrm{s}$ between -1.5 and $1.2 \mathrm{~V} v \mathrm{Ag} / \mathrm{AgCl}$ in acetonitrile solution containing $10 \mathrm{mM}$ of EDOT monomer and $0.5 \mathrm{M} \mathrm{LiClO}_{4}$. The results are displayed in Figure 1(a). The growth of the redox wave in the potential range $-0.5 \mathrm{~V}$ to $1.0 \mathrm{~V}$ was an indicator for the buildup of EDOT films.

\subsection{Electrochemical Behavior of PEDOT}

The electrochemical behavior of PEDOT was investigated by cycling the potential of FTO modified with PEDOT between -1.0 to $1.40 \mathrm{~V}$ vs $\mathrm{Ag} / \mathrm{AgCl}$ in acetonitrile containing $0.5 \mathrm{M} \mathrm{LiClO}_{4}$ at scan rate $0.10 \mathrm{~V} / \mathrm{s}$. The results are displayed in Figure 1(b). It can be noticed that the resulted CV shows an oxidation wave at $\approx-0.1 \mathrm{~V}$

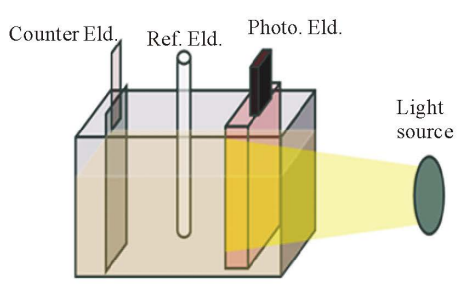

(a)

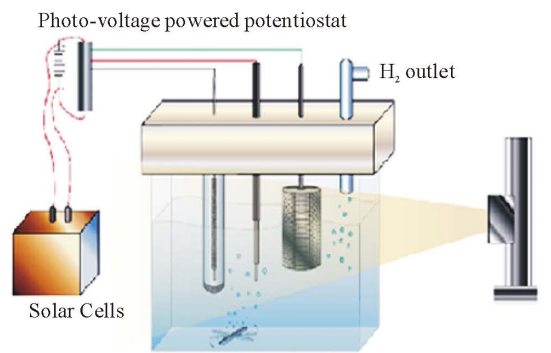

(b)

Diagram 1. Photoelectrochemical cells. (a) for thin film studies; (b) for photolysis of nano-suspensions. 


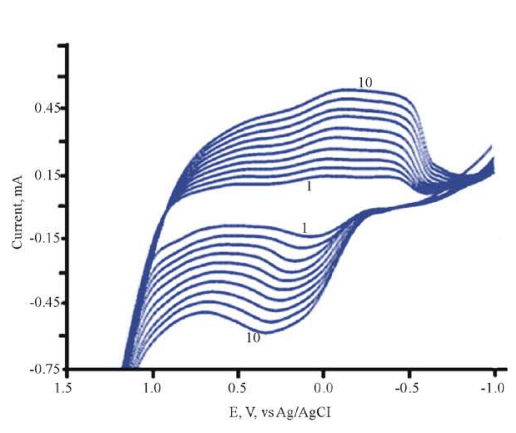

(a)

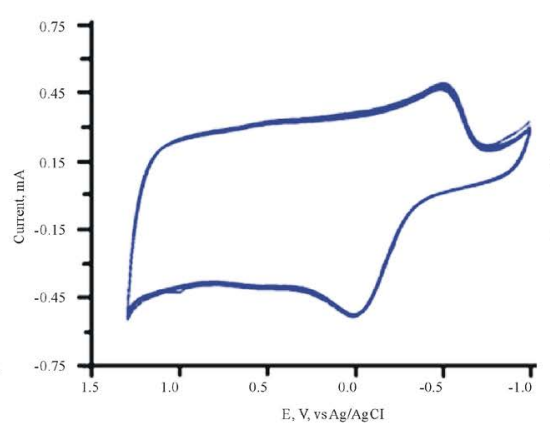

(b)

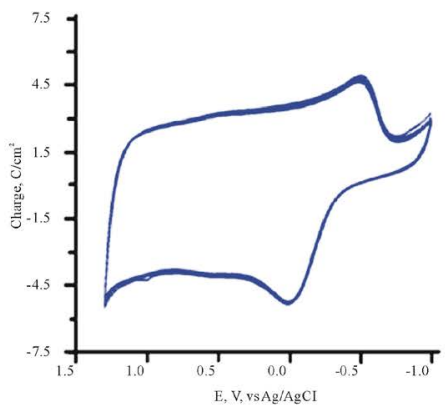

(c)

Figure 1. (a) electropolymerization of 3,4 EDT in ACN containing $\mathrm{LiClO}_{4}$; (b) $\mathrm{CV}$ of ITO/PEDT in ACN/LiClO 4 only, scan rate $100 \mathrm{mV} / \mathrm{s}$; (c) capacitive charge density for FTO/PEDT in ACN containing $\mathrm{LiClO}_{4}$.

and reduction wave at $\approx-0.5 \mathrm{~V}$. it is worth noticing also the very high capacitive current on the thin film of PEDOT. The plot of capacitance vs potential is displayed in Figure 1(c). The large capacitive currents observed for FTO/PEDPT suggest that this assembly could be used as electrodes for super capacitors.

\subsection{Band-Energy Map of PEDOT}

While the band gap of PEDOT depends on the level of doping [16] which controls the absorption peak of the polymer, we choose to use the absorption peak of a neutral polymer film which conditioned at a potential more negative than its first oxidation potential $(<-0.3 \mathrm{~V}$ vs $\mathrm{Ag} / \mathrm{AgCl})$. The absorption peak under these conditions was found to be at $580 \mathrm{~nm}$, corresponding to a band gap of $2.15 \mathrm{eV}$. Ionization potential (IP) and electron affinity (EA) are important parameters to draw the energy map of PEDOT along with the band gap (Eg). These parameters are also needed to explain the electrical and optical properties of the film. Relating electrochemical data such as the onset oxidation potential (E'ox), the onset reduction potential (E'Red), and the band gap leads to an understanding of the integrated energy diagram of the film. Onset potentials can be estimated from the intersection of the two tangents drawn at the rising oxidation current and the background current in the CV using the following formula [17]:

$$
\mathrm{E}_{\mathrm{SHE}} \approx \mathrm{E}_{\mathrm{vac}}+4.6 \mathrm{~V}
$$

$\mathrm{An} \mathrm{Ag} / \mathrm{AgCl}$ was used as a reference electrode $\left(\mathrm{E}^{\circ}=0.197 \mathrm{~V} \approx 0.2 \mathrm{~V}\right.$ vs SHE$)$, therefore $\mathrm{E}_{\mathrm{Ag} / \mathrm{AgCl}} \approx \mathrm{E}_{\mathrm{SHE}}+$ 0.20 , and when $\mathrm{E}_{\mathrm{vac}} \approx 0$, the above Equation can be rewritten as follows:

$$
\mathrm{E}_{\mathrm{Ag} / \mathrm{AgCl}} \approx \mathrm{E}_{\mathrm{SHE}}+0.20 \approx \mathrm{E}_{\mathrm{vac}}+4.8 \mathrm{~V}
$$

As $\quad \mathrm{IP}=\mathrm{E}_{\mathrm{ox}}$ where $\mathrm{E}_{\mathrm{ox}}$ is oxidation potential onset.

$$
\text { When } \mathrm{E}_{\mathrm{ox}}=\mathrm{IP}=\mathrm{E}_{\mathrm{ox}}^{\prime}+\mathrm{E}_{\mathrm{Ag} / \mathrm{AgCl}}
$$

where $\mathrm{E}_{\text {ox }}$ is oxidation potential onset relative to $\mathrm{Ag} / \mathrm{AgCl}$. Substitution from Equation (2) to (3), results in:

$$
\mathrm{IP} \approx \mathrm{eE}_{\mathrm{ox}}^{\prime}+\mathrm{E}_{\mathrm{vac}}+4.8 \mathrm{eV} \text { or IP }=\mathrm{eE}_{\text {ox }}^{\prime}+4.8 \mathrm{eV}
$$

Considering that the energy gap between HOMO (valence band) and LUMO (conduction band) to the band gap (Eg), and the energy gap between the LUMO and vacuum level is the electron affinity (EA), we can write the following Equation:

$$
\mathrm{IP}=\mathrm{EA}+\mathrm{Eg}
$$

By integrating the spectral absorption information with the data obtained from Figure 1 and Equations (1)-(5) and consideration of absorption spectra of PEDOT, a list of photo-electrochemical data for $\mathrm{TiO}_{2}$ and PEDOT were deduced and summarized in Table 1 . The quantities are listed without signs to reflect only their magnitude. The fact that the hole barrier height is large $(\approx 2 \mathrm{eV})$ and greater than the electron barrier height may indicate that charge injection is mediated at the IOI interface through hole transfer. 


\subsection{Photoelectrochemical Behavior of $\mathrm{TiO}_{2} / \mathrm{PEDOT}$}

Thin Solid Form

Cycling the potentials of FTO/TIO $/$ PEDOT in $0.2 \mathrm{M}$ phosphate buffer (pH 6) in the dark and under illumination are displayed in Figure 2. The increase in the reported current during the cathodic scan at $0.2 \mathrm{~V}$ vs $\mathrm{Ag} / \mathrm{AgCl}$ gives an approximate value of the flat band potential of the $\mathrm{ITO} / \mathrm{TiO}_{2} / \mathrm{PEDOT} /$ aqueous electrolyte interface. The variations of photocurrent vs time were studied by measuring the photocurrent generated by this assembly upon illumination at $-0.3 \mathrm{~V}$ vs $\mathrm{Ag} / \mathrm{AgCl}$ he results are displayed in Figure 3, which indicates that a large photocurrent is produced at the first illumination, which dropped in inconsistent ways during the next conductive illumination periods. Such observation indicates changes in the course of charge separation at this IOI assembly.

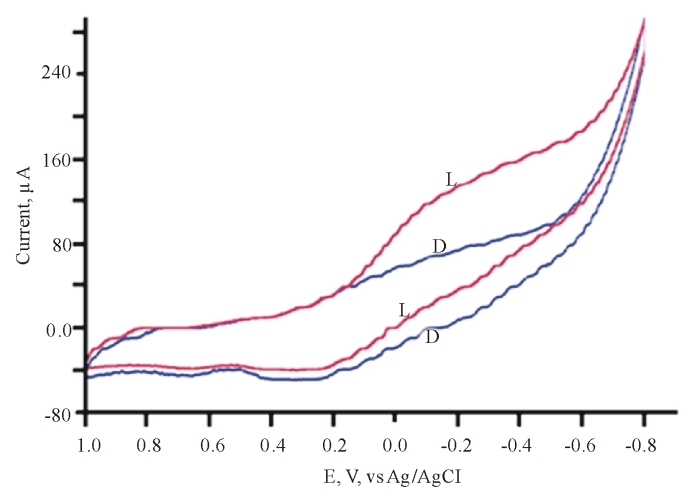

Figure 2. CV of FTO/PEDT in phosphate buffer pH 6 L (light), D (Dark).

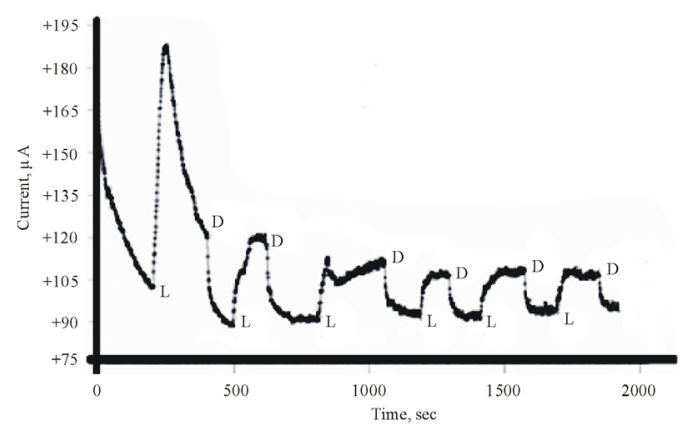

Figure 3. Photocurrent-time curve for ITO/TiO $/$ PEDOT in Phosphate buffer $\mathrm{pH} 6$ containing $10 \mathrm{mM}\left[\mathrm{Fe}(\mathrm{CN})_{6}\right]^{3-}$ at $-0.5 \mathrm{~V}$ vs $\mathrm{Ag} / \mathrm{AgCl} \mathrm{L} \& \mathrm{D}$ donates to Light and dark respectively.

Table 1. photoelectrochemical data for $\mathrm{TiO}_{2} / \mathrm{PEDOT}$ assembly.

\begin{tabular}{|c|c|c|c|}
\hline Property & PEDOT & $\mathrm{TiO}_{2}$ & $\mathrm{TiO}_{2} / \mathrm{PEDOT}$ \\
\hline Band gap, eV & 2.15 & 2.90 & \\
\hline Onset $\mathrm{E}_{\mathrm{ox}}, \mathrm{V}$ vs Ag/AgCl & -0.30 & & \\
\hline Flat band pot., $\mathrm{E}_{\mathrm{fb}}, \mathrm{V}$ vs $\mathrm{SHE}$ & 0.20 & 0.40 & -0.10 \\
\hline Ionization Pot., IP, eV & 4.5 & 7.4 & \\
\hline Electron Affinity EA, eV & $\approx 2.30$ & & \\
\hline$\Phi^{1}$ Hole barrier, eV & $\approx 2.8$ & & \\
\hline $\mathrm{p}^{2}$ Electron barrier, $\mathrm{eV}$ & 1.7 & & \\
\hline
\end{tabular}




\subsection{Effect of Electrolyte Anions on the Photoelectrochemical Behavior of the IOI Assembly}

The results of investigation of the photoelectrochemical behavior of ITO/TiO $/$ PEDOT in $0.20 \mathrm{M}$ acetate pH 6 buffers are displayed in Figure 4 and Figure 5. Figure 4 shows that the current recorded under the dark conditions is greater than that recorded under illumination which is opposite to the behavior recorded in Figure 2. Furthermore, opposite behavior also can be seen by comparing results displayed in Figure 3 and Figure 5 . The change from phosphate $\left(\mathrm{HPO}_{4}^{2-}\right)$ buffer to acetate buffer $\left(\mathrm{CH}_{3} \mathrm{COO}^{-}\right)$clearly alters the nature of the donor/acceptor process and consequently alters the mechanism of charge separation and transfer at the IOI electrolyte interface. Also, the photocurrent reported in presence of acetate (Figure 5) is steady and constant, which is not the case with the photocurrent recorded in phosphate buffer.

\subsection{Photoelectrochemical Behavior of $\mathrm{TiO}_{2} / \mathrm{PNR}$ Aqueous Suspensions}

The theory of the photolysis of aqueous $\left[\mathrm{Fe}(\mathrm{CN})_{6}\right]^{4-}$ has been discussed elsewhere [18]. In this study, aqueous suspensions of pure $\mathrm{TiO}_{2}$ and $\mathrm{TiO}_{2}$ surface-modified with PEDOT in $0.2 \mathrm{M}$ phosphate buffer at pH 6 containing $0.010 \mathrm{M}\left[\mathrm{Fe}(\mathrm{CN})_{6}\right]^{4-}$ were subject to the photolysis process. The potential of the Pt collector electrode was kept constant at $0.000 \mathrm{~V}$ vs Ag/AgCl. The results are displayed in Figure 6. Peak A in Figure 6 is the result of total electrochemical reduction of any $\left[\mathrm{Fe}(\mathrm{CN})_{6}\right]^{3-}$ shown in the following photoreaction:

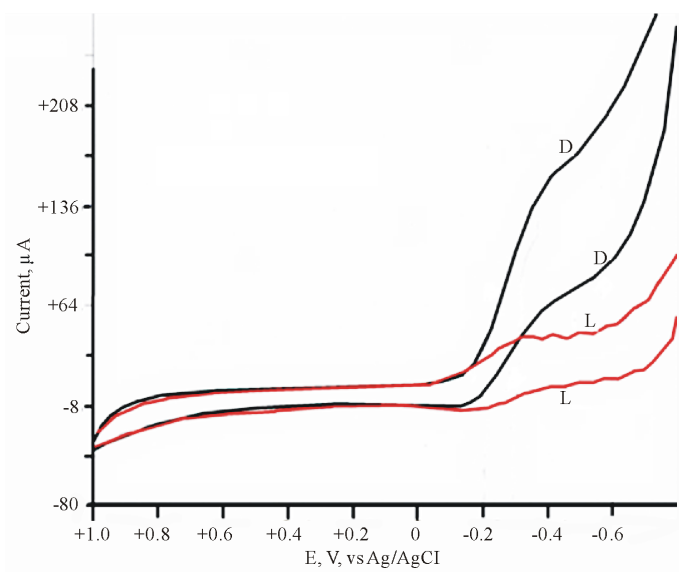

Figure 4. CV of $\mathrm{FTO} / \mathrm{TiO}_{2} / \mathrm{PEDT}$ in Acetate buffer $\mathrm{pH} 6$.
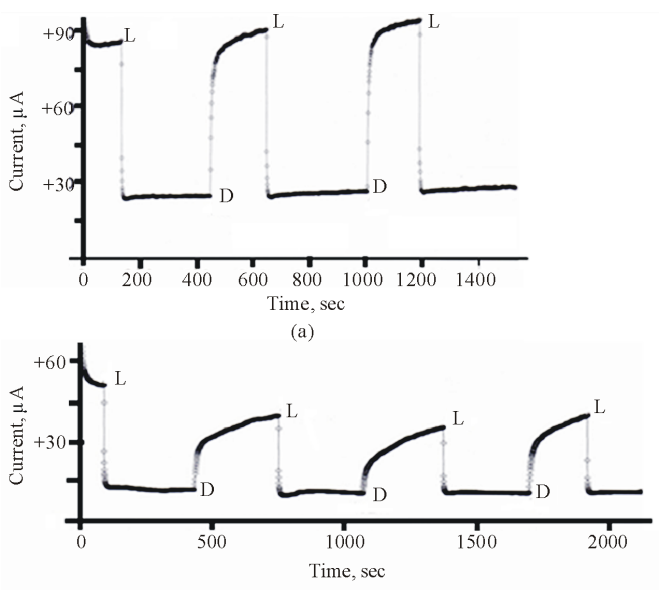

Figure 5. Photolysis $\mathrm{FTO} / \mathrm{TiO}_{2} / \mathrm{PEDT}$ thin film in Acetate buffer $\mathrm{pH} 6$ containing $10 \mathrm{mM}\left[\mathrm{Fe}(\mathrm{CN})_{6}\right]^{4-}$ (a) at $-0.50 \mathrm{~V}$ vs $\mathrm{Ag} / \mathrm{AgCl}(\mathrm{b})$ at $-0.30 \mathrm{~V}$ vs $\mathrm{Ag} / \mathrm{AgCl}(\mathrm{L}$ and $\mathrm{D}$ donate to Light and dark). 


$$
\left[\mathrm{Fe}(\mathrm{CN})_{6}\right]^{4-}+\mathrm{h} v \rightarrow\left[\mathrm{Fe}(\mathrm{CN})_{6}\right]^{3-}
$$

In presence of semiconductor nanoparticles (SC) the following photoreduction reaction takes place:

$$
\left[\mathrm{Fe}(\mathrm{CN})_{6}\right]^{3-}+\mathrm{h} v+\mathrm{SC}(\mathrm{e} / \mathrm{h}) \rightarrow\left[\mathrm{Fe}(\mathrm{CN})_{6}\right]^{4-}
$$

The number of photons consumed in this photoreaction can be calculated from the integration of the green zone portion in Figure 6. The mechanism of the reaction in Equation (7) has been previously discussed [18]. The data listed in Table 2 clearly show that modified $\mathrm{TiO}_{2}$ with PEDOT was more efficient than in the process of photoreduction of $\left[\mathrm{Fe}(\mathrm{CN})_{6}\right]^{3-}$ on native $\mathrm{TiO}_{2}$.

\subsection{Doping PEDOT with $\mathrm{MoO}_{3}$}

Thin solid films of PEDOT doped with $\mathrm{MoO}_{3}$ have been achieved by the occlusion electrodeposition process as described in experimental section. The results are displayed in Figure 7. The growth of both anodic and cathodic peaks currents is indication of the buildup PEDOT impregnated with $\mathrm{MoO}_{3}$. The resulting film has dark bluish appearance. It is well known that $\left[\mathrm{PMo}_{12} \mathrm{O}_{40}\right]^{3-}$ decomposes to produce $\mathrm{MoO}_{3}$ [19] [20].

\subsection{Electrochemical Behavior of ITO/MoO $/ \mathrm{PEDOT}$}

The cyclic voltammetry (CV) of ITO/ $\mathrm{MoO}_{3} / \mathrm{PEDOT}$ assembly in $0.5 \mathrm{M} \mathrm{H}_{2} \mathrm{SO}_{4}(50 \%$ dioxane/water) mixture is displayed in Figure 8 (Trace 1). Occlusion of $\mathrm{MoO}_{3}$ into PEDOT sharply increases the capacitive current and stored greater amount of charge. This observation is supported by the fact that Trace 2 in this figure is the CV for the ITO/PEDOT in the electrolyte only as also illustrated in Figure 1(b). The comparison displayed in Figure 8 confirms the fact that $\mathrm{MoO}_{3}$ is strong electron storage capacity. The large amount of charge represented by the area of Trace 1 compared to that Trace 2, clearly recommend that the $\mathrm{MoO}_{3} / \mathrm{PEDOT}$ assembly can enhance energy storage in both battery and capacitor charge.

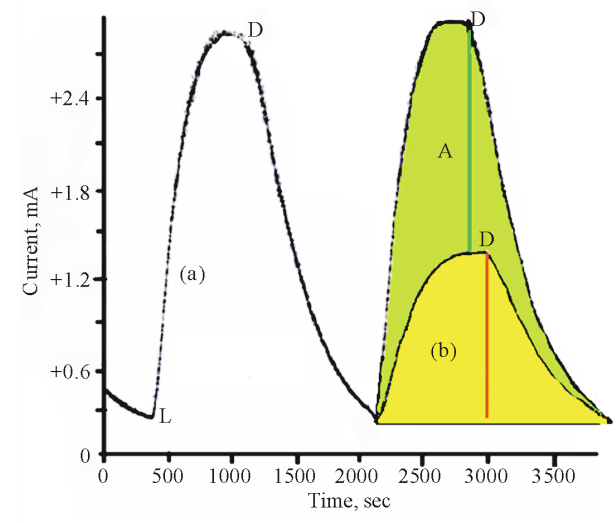

Figure 6. Photolysis of $\mathrm{TiO}_{2} / \mathrm{PEDT}$ in Phosphate buffer $\mathrm{pH} 6$ (a) in aqueous containing $10 \mathrm{mM}\left[\mathrm{Fe}(\mathrm{CN})_{6}\right]^{4-}$ (b) as in $\mathrm{A}+$ addition of nanoparticle suspensions of $\mathrm{TiO}_{2} / \mathrm{PEDT}$ ( $\mathrm{L}$ and $\mathrm{D}$ donate to Light and dark). Green zone represents the photoreduction.

Table 2. Photolysis of Aqueous $10 \mathrm{mM}$ of $\mathrm{K}_{4}\left[\mathrm{Fe}(\mathrm{CN})_{6}\right]$ (Ref) in $0.2 \mathrm{M} \mathrm{HPO}_{4}^{2-}(\mathrm{pH}=6.0)$ in presence of $\mathrm{TiO}_{2} / \mathrm{PEDOT}$

\begin{tabular}{|c|c|c|c|}
\hline Sample & Ref. & Ref. $+\mathrm{TiO}_{2}$ & Ref. $+\mathrm{TiO}_{2} /$ PEDOT \\
\hline Charge (C) due to EC reduction ${ }^{1}$ & 2.423 & 1.646 & 0.925 \\
\hline Charges (C) due to Photochem. Reduction ${ }^{2}$ & & 0.777 & 1.494 \\
\hline$\%$ Photocurrent $^{3}$ & & 32. 07 & 61.7 \\
\hline
\end{tabular}
nanoparticle suspensions.

${ }^{1}$ Calculated from integrating area under Curve A (Figure 6). ${ }^{2}$ Calculated by integrating yellow zone area and green zone area (Figure 6). ${ }^{3}$ Calculated by the ration of photoreduction/EC reduction. 


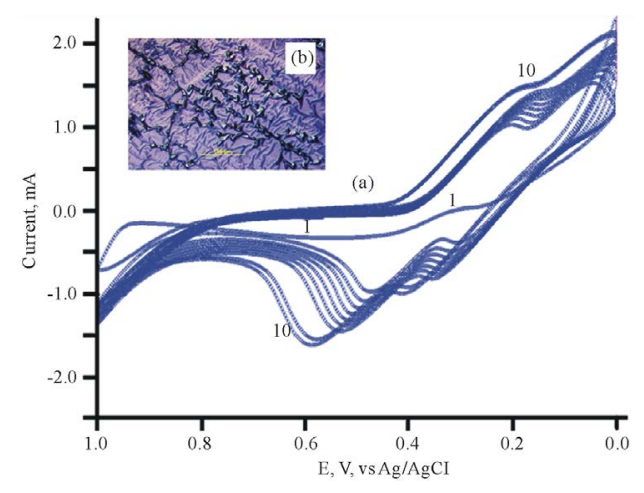

Figure 7. (a) Electrodeposition of $\left[\mathrm{PMo}_{12} \mathrm{O}_{40}\right]^{3-}$ in $\mathrm{FTO} / \mathrm{PEDOT}$ in aqueous $\mathrm{H}_{2} \mathrm{SO}_{4} /$ Dioxane solvent. Inset (b) (scan number is indicated in the figure).

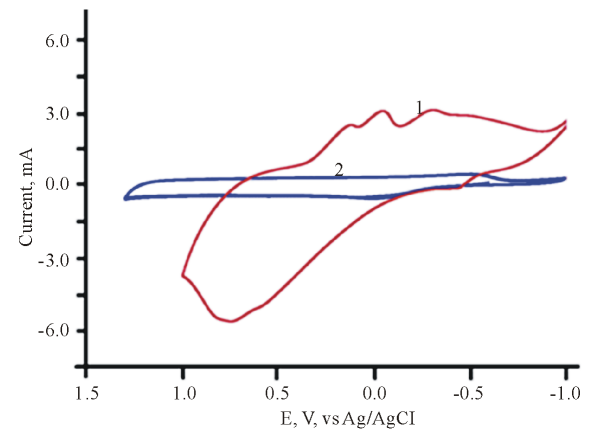

Figure 8. 1) $\mathrm{CV}$ of ITO/PEDT/ $\mathrm{Mo}_{12} \mathrm{O}_{36}$ in aqueous $\mathrm{H}_{2} \mathrm{SO}_{4} /$ Dioxins only, scan rate $100 \mathrm{mV} / \mathrm{s}$; 2) $\mathrm{CV}$ of ITO/PEDT in aqueous $\mathrm{H}_{2} \mathrm{SO}_{4} /$ Dioxins only, scan rate $100 \mathrm{mV} / \mathrm{s}$.

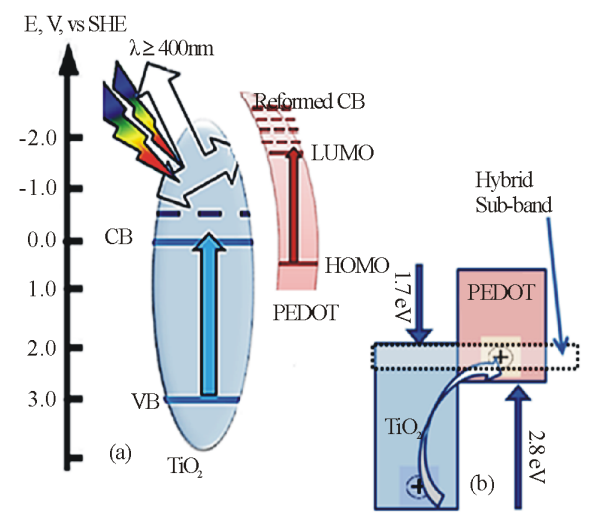

Figure 9. Energy band alignment between $\mathrm{TiO}_{2}$ and PEDOT.

\section{Conclusions}

The $\mathrm{TiO}_{2}$ used in this study is a p-type semiconductor and the properties of PEDOT listed in Table 1 indicate that it is electron donor, its low electron affinity suggests that an Iso p-p junction [21] is formed by creation of a hole accumulation layer in one side and a hole depletion layer on the counter side. The fact that holes in PEDOT's HOMO are at more negative potential than that in $\mathrm{TiO}_{2}$ 's $\mathrm{VB}(2.7 \mathrm{eV})$ as shown in Figure 9, suggests that the charge injection/transfer mechanism took place via hole transfer. This is because more negative potential will attract $\mathrm{TiO}_{2}$ holes to PEDOT side.

The band-energy map of PEDOT has a staggered-band alignment with $\mathrm{TiO}_{2}$ (Figure 9(b)) in IOI assemblies 
as indicated by both electrochemical and spectroscopic data. Such staggered band alignments facilitate the photo-activity of both organic and inorganic semiconductors through hybrid—sub bands leading to more capturing of incident photons at this IOI assembly.

Our studies demonstrated that PEDOT modification of $\mathrm{TiO}_{2}$ enhances the photoactivities of $\mathrm{TiO}_{2} / \mathrm{PEDOT}$ assembly as indicated by the data listed in Table 2. Furthermore, PEDOT/[PMo $\left.\mathrm{PM}_{12} \mathrm{O}_{40}\right]^{3-}$ exhibit high capacitive storage interface that is very useful in energy storage devices.

\section{References}

[1] Behniafar, H. and Yousefzadeh, D. (2015) Chemical Synthesis of PEDOT/Ag Nanocomposites via Emulsion Technique in Silver Colloid. Designed Monomers and Polymers, 18, 6-11. http://dx.doi.org/10.1080/15685551.2014.918018

[2] Hira S.M. and Payne C.K. (2013) Protein-Mediated Synthesis of the Conducting Polymer PEDOT: PSS. Synthetic Metals, 176, 104-107. http://dx.doi.org/10.1016/j.synthmet.2013.05.023

[3] Shaplov, A.S., Ponkratov, D.O., Aubert, P.H., Lozinskaya, P.H., Plesse, C., Maziz, A., Vlasov, P.S., Vidal, F. and Vygodskii, Y.S. (2014) Truly Solid State Electrochromic Devices Constructed from Polymeric Ionic Liquids as Solid Electrolytes and Electrodes Formulated by Vapor Phase Polymerization of 3,4-ethylenedioxythiophene. Polymer, 55, 3385-3396. http://dx.doi.org/10.1016/j.polymer.2014.04.013

[4] Chen, L., Jin, J., Shu, X. and Xia, J. (2014) Solid State Synthesis of Poly(3,4-ethylenedioxythiophene) as Counter Electrode for Dye-Sensitized Solar Cell. Journal of Power Sources, 248, 1234-1240. http://dx.doi.org/10.1016/j.jpowsour.2013.09.139

[5] Carstens, T., Prowald, A., Zein El Abedin, S. and Endres, F. (2012) Electrochemical Synthesis of PEDOT and PPP Macroporous Films and Nanowire Architectures from Ionic Liquids. Journal of Solid State Electrochemistry, 16, 34793485. http://dx.doi.org/10.1007/s10008-012-1814-4

[6] Kupis, J., Migdalski, J. and Lewenstam, A. (2013) Electrochemical Properties of the Poly(3,4-ethylenedioxythiophene) Doped with Taurine Ligands. Electroanalysis, 25, 195-203. http://dx.doi.org/10.1002/elan.201200377

[7] Chu, C.Y., Tsai, C.J.T. and Sun, C.L. (2012) Synthesis of PEDOT-Modified Graphene Composite Materials as Flexible Electrodes for Energy Storage and Conversion Applications. International Journal of Hydrogen Energy, 37, 1388013886. http://dx.doi.org/10.1016/j.ijhydene.2012.05.017

[8] Ghaffari, M., Kosolwattana, S., Zhou, Y., Lachman, N., Lin, M., Bhattacharya, D., Gleason, K.K., Wardle, B.L. and Zhang, Q.M. (2013) Hybrid Supercapacitor Materials from Poly(3,4-ethylenedioxythiophene) Conformally Coated Aligned Carbon Nanotubes. Electrochimica Acta, 112, 522-528. http://dx.doi.org/10.1016/j.electacta.2013.08.191

[9] Pringle, J., Armel, V., Forsyth, M. and MacFarlane, D.R. (2010) In PEDOT Coated Plastic Counter Electrodes for Dye-Sensitized Solar Cells. International Chemical Congress of Pacific Basin Societies, Honolulu, 15-20 December 2010, MATNANO-18.

[10] Rattan, S., Singhal, P. and Verma, A.L. (2013) Synthesis of PEDOT:PSS (Poly(3,4-ethylenedioxythiophene))/Poly (4-styrene sulfonate)/NGPs (Nanographitic Platelets) Nanocomposites as Chemiresistive Sensors for Detection of Nitroaromatics. Polymer Engineering \& Science, 53, 2045-2052.

[11] Wagner, M., O’Connell, C.D., Harman, D.G., Sullivan, R., Ivaska, A., Higgins, M.J. and Wallace, G.G. (2013) Synthesis and Optimization of PEDOT:PSS Based Ink for Printing Nanoarrays Using Dip-Pen Nanolithography. Synthetic Metals, 181, 64-71. http://dx.doi.org/10.1016/j.synthmet.2013.08.012

[12] Karagkiozaki, V., Karagiannidis, P.G., Gioti, M., Kavatzikidou, P., Georgiou, D., Georgaraki, E. and Logothetidis, S. (2013) Bioelectronics Meets Nanomedicine for Cardiovascular Implants: PEDOT-Based Nanocoatings for Tissue Regeneration. Biochimica et Biophysica Acta (BBA)—General Subjects, 1830, 4294-4304. http://dx.doi.org/10.1016/j.bbagen.2012.12.019

[13] Zhai, Y.L., Jin, L.H., Zhu, C.Z., Hu, P., Han, L., Wang, E. and Dong, S.J. (2012) Reversible Electroswitchable Luminescence in Thin Films of Organic-Inorganic Hybrid Assemblies. Nanoscale, 4, 7676-7681. http://dx.doi.org/10.1039/c2nr32623j

[14] Peter, L.M., Upul Wijayantha, K.G., Jason Riley, D. and Waggett, J.P. (2003) Band-Edge Tuning in Self-Assembled Layers of $\mathrm{Bi}_{2} \mathrm{~S}_{3}$ Nanoparticles Used to Photosensitize Nanocrystalline $\mathrm{TiO}_{2}$. Journal of Physical Chemistry B, 107, 8378-8381. http://dx.doi.org/10.1021/jp0303341

[15] Kasem, K. and Dahn, M. (2010) Photodissocaiation of Water Using Colloidal Nanoparticles of Doped Titanium (IV) Oxide Semiconductors for Hydrogen Production. Current Science, 99, 1087-1092.

[16] Kvarnstrom, C., Neugebauer, H., Blomquist, S., Ahonen, H.J., Kankare, J. and Ivaska, A. (1999) In Situ Spectroelectrochemical Characterization of Poly(3,4-ethylenedioxythiophene). Electrochimica Acta, 44, 2739-2750. http://dx.doi.org/10.1016/S0013-4686(98)00405-8 
[17] Roman, L.S., Hummelgen, I.A., Nart, F.C., Peres, F.C. and de Sa, E.L. (1998) Determination of Electroaffinity and Ionization Potential of Conjugated Polymers via Fowler-Nordheim Tunneling Measurements: Theoretical Formulation and Application to Poly (p-Phenylene vinylene). Journal of Chemical Physics, 105, 10614-10620. http://dx.doi.org/10.1063/1.472947

[18] Kasem, K. and Finney, A. (2013). Photoelectrochemical Studies on CdS/Poly Ethyl-Aniline Interfaces. International Journal of Chemistry, 5, 76-86. http://dx.doi.org/10.5539/ijc.v5n3p76

[19] Nair, H., Miller, J.T., Stach, E.A. and Baertsch, C.D. (2010). Mechanism of Dynamic Structural Reorganization in Polyoxometalate Catalysts. Journal of Catalysis, 270, 40-47. http://dx.doi.org/10.1016/j.jcat.2009.12.007

[20] Borras-Almenar, J.J., Coronado, E., Müller, A. and Pope, M. (2001) Polyoxometalate Molecular Sciences. Liuwer Academic Publisher, Dordrechi.

[21] Wang, H.B. and Yan, D.H. (2010) A Heterojunction Is an Interface between Two Semiconductor Materials of Differing Energy. NGP Asia Materials, 2, 69-78. 